\title{
Kastamonu Yöresi Kavak Zararlıları
}

\author{
*Sabri ÜNAL ${ }^{1}$, Fazıl SELEK ${ }^{2}$, Mustafa YAMAN ${ }^{3}$ \\ 1Kastamonu Üniversitesi, Orman Fakültesi, Kastamonu/TÜRKIYE \\ 2Ege Ormancılık Araştırma Enstitüsü Müdürlüğü, İzmir/TÜRKIYE \\ 3Karadeniz Teknik Üniversitesi, Fen Fakültesi, Biyoloji Bölümü, Trabzon/TÜRKIYYE \\ *Sorumlu yazar: sabriunal@kastamonu.edu.tr
}

Geliş Tarihi: 19.04.2016

\begin{abstract}
Özet
Kavak türü, yüksek artım gücü, vejetatif olarak kolayca üretilebilmesi, odununun çeşitli sanayi kollarında kullanılabilmesi ve dünya genelinde yaygın olarak yetiştirilmesi bakımından en önemli hızlı gelişen ağaç türleri arasında yer almaktadır.

Kavak ağacı toprağa dikilmesinden itibaren üretimi yapılıncaya kadar çok çeşitli böceklerin saldırısına uğramakta, ağacın yaprak, sürgün, dal, gövde ve kökleri zarar görmekte ve ağacın hayatiyeti bu durumdan oldukça etkilenmektedir.

Ülkemiz açısından çok önemli bir tür olan kavağın böcek zararlarından en az oranda etkilenmesi için öncelikle hangi tür böcek zararlarına maruz kaldığı kesin olarak bilinmeli, daha sonra da iklim ve çevre faktörleri göz önünde bulundurularak en etkili mücadele metotları ortaya konulmalıdır.

2013-2014 Yılları arasında yürütülen bu çalışmada Kastamonu Yöresi kavak zararlılarının belirlenmesi hedeflenmiş ve çalışma neticesinde literatür bilgileri de değerlendirilerek; Gryllus desertus Pallas, Gryllotalpa gryllotalpa (Linnaeus, 1758), Chionaspis salicis (L.), Lepidosaphes ulmi (L.), Polyphylla fullo (L.), Saperda populnea (L.), Paranthrene tabaniformis (Rott.), Lymantria dispar L., Crepidodera aurata Marsham, Crepidodera aurea (Geoffrey), ve Melasoma populi L. belirlenmiştir.

$M$. populi ve $C$. aurata' nın en yüksek populasyon yoğunluğuna sahip oldukları gözlenmiştir. Ayrıca, Kastamonu Bölgesi'ne ait zararlı böcek türlerini belirlemek amacıyla literatür taraması yapılarak çalışma içinde belirtilmiştir.
\end{abstract}

Anahtar Kelimeler: Kavak, Böcek zararı, Kastamonu

\section{Abstract}

\section{Poplar Pests in Kastamonu Region}

Poplar was accepted as the most important fast growing tree because of its high increment power, easy production vegetative way, using its wood different industrial areas and planted extensive globally.

Poplar tree is attackted by a lot of different insect species. The leaves, shoots, stems, trunks and the roots of the trees are injured. The life sustainability of the trees is very impressed by this damage.

Primarily identifying harmful insect species is very important to minimize the impression of damage for our country. Then impressive control methods should be applied by the taking into consideration of climate factors. As a result of this study carried out during the years 2013-2014 to determine poplar pests in Kastamonu Region, Gryllus desertus Pallas, Gryllotalpa gryllotalpa (Linnaeus, 1758), Chionaspis salicis (L.), Lepidosaphes ulmi (L.), Polyphylla fullo (L.), Saperda populnea (L.), Paranthrene tabaniformis (Rott.), Lymantria dispar L., Crepidodera aurata Marsham, Crepidodera aurea (Geoffrey) and Melasoma populi L. were determined.

It was observed that two species, Melasoma populi and Crepidodera aurata have the higest population densities, respectively. Additionaly, literature review was done to determine harmful insect species belong to Kastamonu Region and indicated on the results section.

Keywords: Poplar, Insect damage, Kastamonu

\section{Giriş}

Dünya nüfus artışı ve sanayinin yaygınlaşması paralelinde odun hammadde talebini de artırmaktadır. Doğal ormanların bu talebi tamamen karşılaması mümkün görülmemektedir. $\mathrm{Bu}$ nedenle dünyada plantasyon ormancılığına çok önem verilmektedir.

Endüstriyel ağaçlandırmaların tesisinde kullanılan kavak türü, yüksek artım gücü, vejetatif olarak kolayca üretilebilmesi, odununun çeşitli sanayi kollarında 
kullanılabilmesi ve dünya genelinde yaygın olarak yetiştirilmesi bakımından en önemli hızlı gelişen ağaç türleri arasında yer almaktadır (Tunçtaner 2008, Birler 2010).

Ülkemizde 3.5 milyon m3/y1l kavak odunu üretilmektedir (Birler 2010).

Tarihin ilk devirlerinden beri zararlı böceklerle insanlar arasındaki savaş sürüp gitmektedir. Kavak ağacı toprağa dikilmesinden itibaren üretimi yapılıncaya kadar çok çeşitli böceklerin saldırısına uğramakta, ağacın yaprak, sürgün, dal, gövde ve kökleri zarar görmekte ve ağacın hayatiyeti bu durumdan oldukça etkilenmektedir. Böcek zararları yere, yıla ve mevsimlere göre pek çok değişiklik gösterdikleri için kesin rakamlarla belirlenememektedir.

Zararlı böceklerin bir kısmı kavağın sağlık durumunun bozulmaya başladığ zamanlarda etkili duruma geçmektedir. Bu durum uzmanların esas neden üzerine odaklanmalarını gerektirmektedir.

Kavaklara karşı birinci derecede zarar yapan böceklerin ağacı zayıflatması diğer organizmaların da kavağa saldırmalarını tetikleyebilmekte, bu da zararın büyümesine ve genişlemesine neden olmaktadır.

Kavak ağaçlandırma ve fidanlıklarında en s1k rastlanan yaprak zararlısı böcek türleri; Chrysomela populi L., Kavak yaprak böceği (Coleoptera: Chrysomelidae), Hyphantria cunea (Drury), Amerikan beyaz kelebeği (Lepidoptera: Arctiidae), Leucoma salicis (L.), Kavak örücüsü (Lepidoptera: Lymantriidae), Lymantria dispar (L.), Sünger örücüsü (Lepidoptera: Lymantriidae), Nycteola asiatica Krul. Yeşil ağ tırtılı (Lepidoptera: Noctuidae) olarak, gövde ve dal zararlıs1 böcek türleri; Paranthrene tabaniformis (Rott.) Saydam kanatlı kavak kelebeği (Lepidoptera: Aegeriidae), Melanophila picta (Pall.), Sarı lekeli kavak süslü böceği (Coleoptera: Buprestidae), Agrilus ater L., Altı noktalı kavak süslü böceği (Coleoptera: Buprestidae), Crytorrhynchus lapathi (L.), Kızılağaç hortumlu böceği (Coleoptera: Curculionidae), Chionaspis salicis (L.), Söğüt koşnili (Homoptera: Diaspididae), Lepidosaphes ulmi (L.), Virgül koşnili (Homoptera: Diaspididae), Kök zararlısı böcekler ise; Melolontha melolontha (L.),
Adi mayıs böceği (Coleoptera:Scarabaeidae) Capnodis miliaris Klug., Kavak kök süslü böceği (Coleoptera: Buprestidae) olarak bildirilmektedir (Selek ve ark. 2014).

Ülkemiz açısından çok önemli bir tür olan kavağın böcek zararlarından en az oranda etkilenmesi için öncelikle hangi tür böcek zararlarına maruz kaldığı kesin olarak bilinmeli, daha sonra da iklim ve çevre faktörleri göz önünde bulundurularak en etkili mücadele metotları ortaya konulmalıdır.

Yukarıda belirtilen nedenlerden ötürü Kastamonu yöresine ait kavak zararlısı böceklerin belirlenmesi için literatür taraması yapılmış, böcekler bulgular kısmında belirtilmiş̧ir. Böcek zararlarının devamlılığ ve yeni türlerin her dönem gelebileceği gibi nedenlerden dolayı ilerleyen dönemlerde çeşitli gözlem ve tuzak metotları kullanılarak bu tür çalışmalara devam edilmelidir.

\section{Materyal Ve Yöntem}

Materyal

Araştırmanın materyalini Kastamonu yöresi merkez ve ilçelere bağlı köylerindeki değişik mevkilerde bulunan kavak ağaçlarının yaprak, dal, sürgün ve gövdelerinde tespit edilen böcek türleri oluşturmaktadır.

Çalışmada Kastamonu yöresinde kavak türlerinde daha önce tespit edilen türler literatürden derlenerek verilmiştir. Ayrıca proje kapsamında arazide yapılan çalışmalar sirasinda yörede bulunan türler de özellikle yaygınlık durumu göz önüne alınarak belirtilmiştir.

\section{Yöntem}

\section{Örneklerin toplanması}

Kastamonu yöresinde bulunan kavak ağaçlarında zarar meydana getiren türlerin tespit edilmesi amaciyla 2013 ve 2014 yılları Nisan-Ekim ayları arasındaki dönemde arazide periyodik olarak inceleme ve gözlemler yapılmıştır. Bu amaçla kavak yaprak ve gövdeleri üzerinde görülen küçük türler aspiratör veya emgi şişe ve tüplerinden yararlanılarak toplanmıştır. Diğer kavak zararlılarının yumurta, larva pupa ve erginleri ise gövde, yaprak ve dallardan alınarak laboratuvara getirilmiş; erginler elde edilmek suretiyle teşhise hazır hale getirilmiştir. 


\section{Bulgular \\ Gryllus desertus Pallas (Orthoptera: Gryllidae) \\ Böceğin erginleri 13-14 $\mathrm{mm}$ uzunluğunda, hafif tüylü ve siyah toprak rengindedir. Kanat örtüleri karın halkalarından daha kısadır. Kanatları çok kısalmış veya tamamen kanatsız erginlerine de rastladığı bilinmektedir (Sekendiz 1974).}

\section{Türkiye'deki yayılıșı:}

Böcek, Türkiye'de Adana, Adıyaman, Afyonkarahisar, Ağrı, Aksaray, Amasya, Ankara, Antalya, Artvin, Balıkesir, Bartın, Bilecik, Bingöl, Bolu, Bursa, Çankırı, Çorum, Edirne, Elazığ, Erzincan, Erzurum, Diyarbakır, Hatay, Isparta, İstanbul, İzmir, Kahramanmaraş, Karabük, Karaman, Kars, Kastamonu, Kayseri, Kırşehir, Kırıkkale, Kırklareli, Kocaeli, Konya, Kütahya, Malatya, Manisa, Muş, Nevşehir, Niğde, Samsun, Sakarya, Sinop, Şanlıurfa, Tekirdağ, Tunceli yörelerinde bulunmaktadır (Ünal 2006).

Böcek yeni süren kavak çeliklerinin tomurcuk ve filizlerini kemirerek zarar yapmaktadır (Sekendiz 1974).

Böcek y1lda bir generasyon vermekte, son dönem larvaları toprağın $40 \mathrm{~cm}$ derinliğinde kışlamakta, larvalar erken ilkbaharda topraktan çıkmakta, Temmuz sonunda erginleşmektedir. Erginler yumurtalarını birer birer veya 3-5'i bir arada olmak üzere Temmuz sonunda birakmakta kısa bir zaman sonra da ölmektedir (Url1, 2014).

Gryllotalpa gryllotalpa (Linnaeus, 1758) (Orthoptera: Gryllotalpidae)

Böceğin vücudu kadife gibi kısa tüylerle kaplı olup kırmızımtrak kahverengi veya kirli koyu esmer bir renge sahiptir. Üst kanatları kısa saydam ve damarları belirgindir. Alt kanatları iyi gelişmiş, yelpaze gibi kendi üzerine katlanmış olup vücut boyunca uzanmaktadır. Ön bacakları toprağı kazmak için özel bir şekil almıştır. Vücut uzunluğu 4$6 \mathrm{~cm}$ 'dir.

\section{Türkiye'deki yayılışı:}

Böcek yurdumuzun hemen hemen her yerinde değişik yoğunluklarda bulunmaktadır (Kaplan ve Yücel 2014'den atfen Bodenheimer 1958, Lodos 1975).
Böcek kavak fidanlıklarında fidan köklerini kemirerek zarar yapmaktadır.

Böceğin erginleri Haziran ve Temmuz aylarında $20-30 \mathrm{~cm}$. derinlikte toprak ve kök parçalarından hazırladıkları 2-3 cm çapındaki küremsi yuvalara 200-250 adet yumurta birakmaktadır. Yumurtadan 20 gün sonra çıan larvalar yuvada toplu halde bulunmakta ve Ekim ayına kadar iki deri değiştirmektedirler. Ekim ayında galerilere dağılmakta üçüncü deriyi de değiştirip toprağın derinliklerine inmektedirler. Böcek ilkbaharda toprak yüzeyine paralel $2 \mathrm{~cm}$ derinlikteki galeriler içinde aktif olup Nisan'da erginleşmekte Mayıs ve Haziranda çiftleşmektedir (Sekendiz 1974).

Chionaspis salicis (Linnaeus 1758) (Homoptera: Diaspididae)

Ergin dişinin kabuğu düzensiz şekilli fakat genellikle geniş armut şeklinde, oldukça konveks ve beyazımsı renktedir. Dişilerde 2-2.5 $\mathrm{mm}$ boyunda olan kalkan, oval, grimsi veya sarımsı beyaz renktedir. Erkeklerde puparium beyaz, 0.5-1 $\mathrm{mm}$ boyundadır. Uzunluğuna 3 çizgi taşımaktadır. Dişisi şarap kırmızısı, erkek parlak portakal rengindedir (Çanakçığlu ve Mol 1998, Sekendiz 1974).

Türkiye'deki yayılışı:

Böcek Türkiye'de Kastamonu, Çankırı, Kayseri, Ankara, Niğde, Bolu, Kars, Denizli, Konya, Sivas-İmranl, Erzincan, BursaUludağ İzmit ve Çankırı yörelerinde tespit edilmiştir (Sekendiz 1974, Çanakçıoğlu ve Mol 1998, Şimşek 1999). Böcek bitkilerin özsuyunu emerek beslenmektedir.

Böcek yılda bir döl vermekte, kış1 yumurta döneminde geçirmektedir. İlkbaharda oluşan larvalar gelişerek mayıs ya da haziranda erginleşmektedirler. Ergin dişiler Ağustos ya da Eylül'de yumurta bırakmaktadırlar (Çanakçıoğlu ve Mol 1998).

\footnotetext{
Lepidosaphes ulmi (Linnaeus 1758) (Homoptera: Diaspididae)

Kabukları virgüle benzemektedir, dişiler 3-4.5 mm uzunlukta ve $1.2-2 \mathrm{~mm}$ genişliktedir. Çıplak dişinin vücudu armut şeklinde sarımsı beyaz olup pygidium kısmı koyu sarı renktedir. Erkeklerin kalkanı 1.6
} 
$\mathrm{mm}$ uzunluk ve $0.5 \mathrm{~mm}$ genişliktedir (Çanakçıŏlu ve Mol 1998).

\section{Türkiye'deki yayılışı:}

Böcek Türkiye'de Antalya, Antakya, İzmir, Ankara, Bursa, Niğde, Konya, Mardin, Bolu, Elazığ, Sivas-İmranlı, Kastamonu, Amasya, Kayseri, Balıkesir, İzmit, İstanbul, Trabzon, Çorum ve Merzifon'da tespit edilmiştir (Çanakçıŏlu ve Mol 1998, Sekendiz 1974).

Böcek ağaçların gövde, kalın ve ince dallarında, sürgün ve tomurcuklarında ender olarak da yapraklarında zarar yapmaktadır. Yoğun populasyonların bulunduğu ağaçların gövde ve dalları koşnil tarafindan tamamen örtülmektedir. Yoğun beslenme sonucu ağaçların kabukları çatlamakta ve tüm ağaçta gelişme durmaktadır. Yapraklar küçülmekte, meyveler deforme olmakta ve küçük kalmaktadır.

Böcek yılda iki generasyon vermekte, kış1 yumurta döneminde geçirmekte, ilkbaharda yumurtadan çıkan larvalar beslenmekte ve vücutları üzerinde kabuk oluşturmaktadırlar. Erginler Haziran ve Temmuz'da olgunlaşmakta ve çiftleșmektedir. Dișiler yumurtalarını kabuk altına bırakmaktadır. Yumurtalar ortalama 2 hafta içinde açılmakta ortaya çıkan larvalar gelişerek sonbahar başlangıcında ergin hale geçmektedir. $\mathrm{Bu}$ dönemde erkek ve dişiler çiftleşmekte daha sonra da dişiler kışı geçirecek olan yumurtalarını kabuk altına birakmaktadırlar (Çanakçıŏglu ve Mol 1998).

\section{Polyphylla fullo (Linnaeus 1758)} (Coleoptera: Scarabaeidae)

Böcek büyüklüğü 25-40 $\mathrm{mm}$ arasında olup, boyun kalkanı ve kanat örtüleri, kırmızımtrak kahverengi ile koyu kahverengi arasında değişmekte ve üzerinde düzgün olmayan serpilmiş beyazımsı lekeler bulunmaktadır. Antenler 10 parçadan oluşmakta, anten topuzu erkeklerde oldukça iri ve 7 yapraktan, dişilerde ise küçük ve 5 yapraktan oluşmaktadır (Çanakçıŏglu ve Mol 1998).

\section{Türkiye'deki yayılışı:}

Böcek, İstanbul, Yalova, Bursa, Kastamonu (Sekendiz 1974'den atfen Schimitschek 1944), İzmit, Karasu, Yenişehir, İnegöl, Lüleburgaz, Eğirdir ve
Akşehir'de zarar yapmaktadır (Sekendiz 1974).

Böceğin erginleri yaprakları yiyerek, larvaları kökleri kemirerek zarar yapmaktadır. Özellikle çayırlıktan kavak kültürüne dönüştürülmüş yerlerde ve fidanlıklarda önemli zararlar yapmaktadır.

Böceğin uçma zamanı Mayıs-Ağustos aylarına rastlamaktadır. Dişiler yumurtalarını toprağın 10-15 cm derinliğine bırakmaktadır. Yumurta dönemi 1-5 ay sürmektedir. Yumurtadan çıkan larvalar önce ince bitki kökleriyle beslenmekte sonra kazık kökleri de kemirmektedirler. Kış1 toprağın derinliklerinde geçirmektedirler. Olgunlaşan larvalar toprak içinde $30-35 \mathrm{~cm}$ derinlikte açtıkları yuvalarda pupalaşmaktadır. Böcek generasyonunu 2-3 yilda tamamlamaktadır (Çanakçığlu ve Mol 1998).

\section{Saperda populnea (Linnaeus 1758) (Coleoptera: Cerambycidae)}

Böceğin boyu 10-14 mm olup vücudu silindir şeklinde ve üzerinde yeşilimsi gri renkte seyrek ince tüyler bulunmaktadır. Boyun kalkanı üzerinde sarımtrak renkli pulların meydana getirdiği uzunlamasına 3 adet çizgi bulunmaktadır. Kanat örtüleri üzerinde 4-5 adet sarı lekeler mevcuttur.

\section{Türkiye'deki yayılışı:}

Böcek Türkiye'nin hemen her yöresinde bulunmaktadır (Çanakçıŏlu ve Mol 1998, Schimitschek 1953).

Böcek zarar yaptığ 1 fidan ve sürgünlerde şişkinlikler meydana getirmekte, bu sürgün ve gövdelerin kuruyarak ölmesine sebep olmaktadir.

Böceğin uçma zamanı mayıs ve haziran ayına rastlamaktadır. Yumurtadan çıkan larva önce kabuk altında gövde eksenine dik olarak yarım halka şeklinde bir yol açmaktadır. Böcek kışı bu larva yolu içinde geçirmekte, ertesi ilkbaharda da dalın öz kısmına girerek düşey istikametlerde 5-10 $\mathrm{cm}$ yollar açmakta ve bu yolların sonunda tekrar kışlamaktadır. Ertesi ilkbaharda geriye dönerek pupalaşmakta ve erken ilkbaharda yumurta bırakılan kısmın tam karşısından açtığ1 daire şeklindeki delikten dişarıya çıkmaktadır. Bu duruma göre böceğin 2 yıllık bir generasyonu vardır (Sekendiz 1974). 


\section{Paranthrene tabaniformis (Rottemburg 1775) (Lepidoptera: Sesiidae)}

Böceğin ergin kanat açıklığ $24-35$ mm arasındadır. Ön kanatları esmer kahverengi pullarla örtülüdür. Arka kanatları saydam ve belirgin bir şekilde damarlıdır. Gövde madeni mavi renktedir. Dişilerde 2. ve 4., erkeklerde 2., 4., 6. ve 7. karın halkalarının arka kenarları açık sarı renktedir.

\section{Türkiye'deki yayılıșı:}

Böcek Türkiye'nin hemen her yerinde bulunmaktadır (Güler ve Can 1995/1). Şimşek (2002) söz konusu zararlının Çankırı'da (Kenbağ Orman Fidanlığı) bulunduğunu ifade etmektedir.

Böcek kavaklara fidan ve genç ağaç döneminde zarar yapmaktadır. Böceğin larvası gövde içinde galeriler açmakta fidan veya ağaç fizyolojik zayıflığa uğramakta, kurumakta ve kırılmaktadır.

Böceğin ergin çıkışları hava sıcaklığının 20-25 ${ }^{\circ} \mathrm{C}^{\prime}$ ye ulaşmasıyla başlamaktadır. Bu durumda erginler Mayıs başında çıkmaya başlamakta, Haziran ortası ve temmuz sonu arasındaki dönemde en yüksek düzeye ulaşmaktadır (Güler ve Can 1995/2).

Dişiler çıktıktan sonra hemen çiftleşmekte, ortalama 50-60 adet yumurtalarını gövde üzerindeki yara yerlerine, kavakların yerden 1-1,5 m'lik kısımlarına bırakmaktadır. Yumurtalar 9-14 gün içinde açılmakta, yumurtayı terk eden larva süratle kabuk altına geçmekte, oradan ağacın eksenine dik yönde galeri açarak öze ulaşmakta ve galeri açmaya devam etmektedir. Larva galeri içinde yaz sonuna kadar 10 ay beslenmekte ve bu dönemde kış1 geçirmektedir. İlkbaharda tekrar beslenmeye başlamakta nisan sonunda olgunlaşmakta, uçma deliğini açmakta ve pupalaşmaktadır. 15 günlük pupa devresinden sonra ergin olarak fidanı terk etmektedir (Güler ve Can 1995/3).

Bulaşı fidanların içerisinde larva ve pupa dönemlerini tamamlayıp erginin çıktığı, gövde üzerindeki şişkinliklerden kolayca anlaşılabilmektedir. Bulaşık fidanların görünüşü de bozulduğu gibi, fidanın direnci zayıfladığından şiddetli rüzgarlarda bulaşık noktadan kolayca kırilabilmektedir. Aynı çalışma sırasında Saydam kanatlı kavak kelebeği, bazı fidanlıklarda \%30'a varabilen bulamaşlara sebep olup fidan üretimini olumsuz yönde etkilediği, bulaşık fidanların imha edilmesi nedeniyle maliyetin yükseldiği, tüm çabalara rağmen bazen gözden kaçabilen bulaşık fidanlarla, zararlının temiz bölgelere de bulaşabildiği, ayrıca bazı yaşlı kavak alanlarının kavak üretimi yapılan fidanlıklar bakımından sürekli bulaşma kaynağını oluşturduğu, kelebek uçuşları uzun bir dönemi kapsadığından geleneksel ilaçlama yöntemiyle zararlının kontrol altına alınamadığı ve gereksiz ilaçlamalarla doğal dengenin olumsuz yönde etkilenmesi gibi ağır sorunların ortaya çıkmasına da neden olduğu anlaşılmıştır (Şimşek, 2005).

\section{Lymantria dispar Linnaeus 1758 (Lepidoptera: Lymantriidae) \\ Böceğin erkek erginleri grimsi kahverengi} ile kırmızımtırak kahverengi arasında değişmekte olup kanat açıklığ $\quad 35-40$ mm'dir. Antenleri iki taraflı tarağımsıdır. Dişi erginler iri ve kaba yapıll, kirli beyaz renkte olup kanat açıklığı 55-70 mm'dir. Antenleri iplik şeklinde tek taraflı tarağımsıdır (Çanakçıoğlu ve Mol 1998).

\section{Türkiye'deki yayılışı:}

Böcek Türkiye'nin hemen her bölgesinde yayılmıştır (Çanakçıŏlu ve Mol 1998).

Böceğin larvaları kavak yapraklarını yemek suretiyle zarar yapmaktadır. Böcek yılda bir generasyon vermekte olup kış1 yumurta döneminde geçirmektedir. Yumurtalar Nisan'da açılmaya başlamakta ve yumurtadan çıkan larvalar beslenmeye başlamaktadır. Böcek Haziran'da pupalaşmakta, pupa dönemi 15-20 gün sürmektedir. Erginler Haziran sonunda çıkmaya başlamaktadır.

\section{Araştırma Bulguları}

$\mathrm{Bu}$ bölümde sunulan kavak zararlılarına ait yumurta larva, pupa ve/veya erginler, 2013 ve 2014 yıllar1 arasında Kastamonu yöresinde yapılan arazi çalışmaları sonucunda elde edilmiştir. 
Crepidodera aurata Marsham 1802 (Coleoptera: Chrysomelidae)

Böceğin erginleri 2.5-3.5 mm boyunda olup baş ve boyun kalkanı koyu metalik yeşil ya da mavimsi yeşildir. Antenleri sarımsı kırmızı olup uca doğru koyulaşmakta ve vücut uzunluğunun yarısına ulaşmaktadır. Kanat örtülerinin üzeri çok belirgin nokta siralidir.

Türkiye'deki yayılışı:

Böcek Türkiye'de İzmit-Sapanca, İstanbul-Belgrat Orman1, AnkaraKızılcahamam, Bolu (Düzce, Gerede),
Zonguldak-Ereğli, Bartın, Kastamonu (Daday, Araç), Edirne, Adapazarı, Balıkesir, Kurklareli ve Samsun bölgelerinde yayılmıştır (Çanakçıŏlu ve Mol 1998, Kaygin ve Y1ldız, 2007, Ünal ve ark. 2014).

Böceğin erginleri kavak yapraklarında irili ufaklı delikler açarak zarar yapmakta, ayrica ilkbaharda tomurcukları kemirmektedirler.

Böceğin erginleri Mayıs başından Eylül sonuna kadar görülmekte ve kışı toprakta geçirmektedir. Kastamonu bölgesinde Nisan ayında tespit edilmiştir (Çizelge 1, Şekil 1).

Çizelge 1. C.aurata 'nın Kastamonu yöresinde tespit edildiği tarih, yer ve örnek sayısı

\begin{tabular}{|l|l|l|}
\hline Örnek tarihi & Lokalite & İncelenen örnek sayısı \\
\hline 14.04 .2013 & Kastamonu & 16 (Ergin) \\
\hline 26.04 .2014 & Kastamonu-Bekdemirekşi & 113 (Ergin) \\
\hline
\end{tabular}

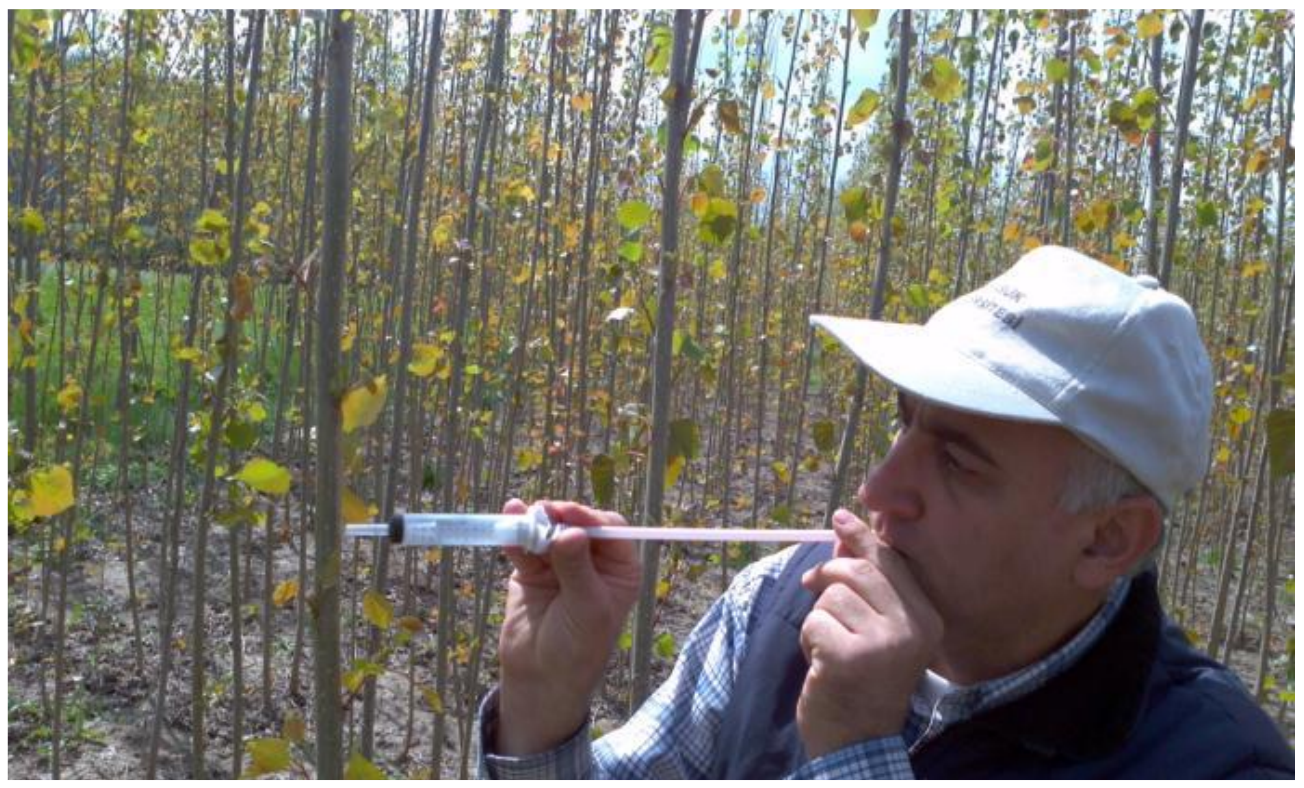

Şekil 1. C. aurata erginlerinin kavak gövdelerinden aspiratör ve emgi şişesiyle toplanması.

Crepidodera aurea (Geoffroy, 1785) (Coleoptera: Chrysomelidae)

Böceğin erginleri 2,5-4 $\mathrm{mm}$ büyüklüğündedir. Gövde parlak maviyeşilden bakır kırmızısına kadar değișebilmektedir. Ön göğsünün alt kenarında uzunluğuna iki çukurcuk vardır. Arka femurları çok şişkindir. Bu sayede 20-
$30 \mathrm{~cm}$ kadar sıçrayabilmektedirler (Sekendiz 1974, Çanakçıŏlu H., Mol T. 1998).

\section{Türkiye'deki yayılışı:}

Böcek Türkiye'de Keşan, Kırklareli, İstanbul, İzmit, Adapazarı, Bursa-Yenişehir, Karacabey, Mustafakemalpaşa, BoluMengen, Yeniçağa, Devrek, Kızılcahamam, 
Bolu, Gerede, Balıkesir, Gönen, ZonguldakEreğli, Bartın, Kastamonu yörelerinde belirlenmiştir (Sekendiz 1974, Çanakçıŏlu ve Mol 1998). Böceğin erginleri ilkbaharda taze kavak yapraklarını alt yüzünden yaprak damarları kalacak şekilde yemek suretiyle zarar yapmaktadır (Sekendiz 1974).Böcek ergin dönemde kabuk çatlakları, mekanik yaralar gibi çeşitli yerlerde kışlamakta, hava sicaklığ $15{ }^{\circ} \mathrm{C}$ üzerine gelince aktif hale geçmektedir (Sekendiz 1974). Kastamonu yöresindeki arazi çalışmalarımız sırasında böceğin erginlerine sık olarak rastlanmıştır.

\section{Chrysomela (Melasoma) populi Linnaeus $1758 \quad$ (Coleoptera: Chrysomelidae)}

Böceğin erginleri 9.94-10.26 $\mathrm{mm}$ büyüklüğünde olup konkav ve oval bir yapıdadır. Kanat örtüleri kiremit kırmızısı renktedir ve örtülerin ucunda siyah birer nokta bulunmaktadır. Böceğin gövde ve bacakları parlak mavi-yeşil veya esmer toprak rengindedir (Sekendiz 1974).

Çizelge 2. C. (M.) populi’ nin Kastamonu yöresinde tespit edildiği tarih, yer ve örnek sayısı

\begin{tabular}{|c|l|l|}
\hline Örnek Tarihi & \multicolumn{1}{|c|}{ Lokalite } & \multicolumn{1}{|c|}{ Incelenen Örnek Sayısı } \\
\hline 19.04 .2013 & Bekdemirekşi & 20 (Ergin) \\
\hline 27.04 .2013 & Bekdemirekşi & 48 (Ergin) \\
\hline 18.06 .2014 & Bekdemirekşi & 170 (Ergin) \\
\hline 23.06 .2014 & Bekdemirekşi & 46 (Ergin) \\
\hline 30.06 .2014 & Bekdemirekşi & 61 (Ergin) \\
\hline 04.09 .2014 & Alibeşe Köyü & 50 (Ergin), 29 (Larva) \\
\hline 04.09 .2014 & Alibeşe Köyü & 35 (Ergin) \\
\hline 19.04 .2013 & Bekdemirekşi & 20 (Ergin) \\
\hline 27.04 .2013 & Bekdemirekşi & 48 (Ergin) \\
\hline
\end{tabular}

Türkiye'deki yayılıșı:

Böcek Türkiye'de Trakya mıntıkasında, İstanbul dolaylarında, Trabzon'da (Sekendiz 1974 'den atfen Acatay 1943, Schimitschek 1944), İzmit, Düzce, Sinop-Bektaşağa, (Sekendiz 1974), Bozdăg, Bilecik, Bursa, Denizli, Sarıkamış, Kars, İzmir, Bolu, Taşköprü, Aydın, Bitlis, Adapazarı, Zonguldak, Bartın, Balıkesir, Çanakkale, Kırklareli, İpsala, Çatalca (Aslan,1997, Çanakçıŏlu ve Mol 1998), SamsunÇarşamba, Vezirköprü ve Kastamonu (Çizelge 2)'da yayılmıştır (Ünal ve ark. 2014).

Böceğin ergin ve larvaları kavak yapraklarını yiyerek zarar yapmaktadır. Zarar nedeniyle sürgünlerde dallanmalar başlamakta ve odunun değeri düşmektedir. Sürgünlerin odunlaşması yeterli düzeyde olmadığından ağaçlar don zararlarına karşı hassaslaşmaktadır.

Böceğin erginleri kışı toprakta, ölü örtü altında, ağaç kovuklarında ve benzeri yerlerde geçirmektedir. Erginler ilkbaharda tomurcukların patlamasıyla birlikte 2-3 gün kavak yapraklariyla beslenmekte sonra çiftleşerek 20-70'li gruplar halinde yumurtalarını bırakmaktadırlar. İklim şartlarına göre 5-12 gün sonra yumurtadan çıkan larvalar beslenmeye başlamaktadır (Şekil 2). Larva dönemi 3 hafta sürdükten sonra pupalaşma başlamaktadır. Pupa dönemi 10 gün sürmektedir. Böcek yılda 2-3 generasyon vermektedir.

\section{Tartışma ve Sonuç}

$\mathrm{Bu}$ çalışmada Kastamonu yöresinde bulunan kavak ağaçlarında zarar meydana getiren türler konusunda elde edilen sonuçlar, literatür taramasıyla birlikte sunulmuştur. Kavak zararlısı türlerin belirlenmesi bu böceklerle yapılacak mücadeleler için temel olabilir. Kastamonu yöresinde literatür ve araștırma sonuçlarına göre bulunan kavak zararlıları 4 takım ve 6 familyadan 11 tür olarak Gryllus desertus Pallas, Gryllotalpa gryllotalpa (Linnaeus, 1758), Chionaspis salicis (L.), Lepidosaphes ulmi (L.), Polyphylla fullo (L.), Saperda populnea (L.), Paranthrene tabaniformis (Rott.), Lymantria 
dispar L., Crepidodera aurata Marsham, Crepidodera aurea (Geoffrey), ve Melasoma

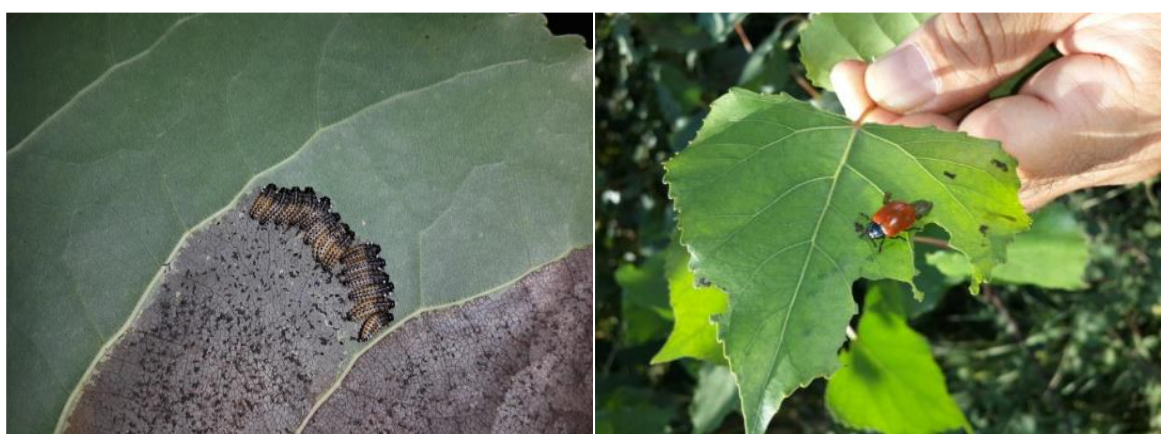

Şekil 2. C. populi L. larva ve erginleri

Yapılan araştırma Kastamonu'da kavak zararlılarının tespitine yönelik nadir çalışmalardandır. Tespit edilen türler söz konusu alanda bulunan kavak zararlılarının tümünü yansıtmayabilir. Yöredeki üreticilerin kavak plantasyonlarında oldukça fazla kimyasal ilaç kullanması bu ekosistemdeki böcek türlerinde azalmaya neden olmuş olabilir. Bu konuda gelecekte kavak alanlarında ana zararlılar üzerinde farklı yöntemler kullanılarak (1şık tuzakları, türe özgü feromon tuzaklar vb.) başka çalışmaların yapılması önerilebilir.

\section{Teşekkür}

Bu çalışma 1120807 numaralı TÜBİTAK projesi tarafından desteklenmiştir.

\section{Kaynaklar}

Anonim2015:http://www.entomart.be/images/ INS-0988.jpg

Aslan İ., 1997. Erzurum ilinde Söğüt (Salix spp.) ve Kavak (Populus spp.)' larda Zararlı Olan Yaprak Böcekleri (Coleoptera, Chrysomelidae) Üzerinde Bir Araştırma. İ.Ü. Orman Fakültesi Dergisi B (47-3) 1-11, İstanbul.

Birler A., S. 2010. Türkiye'de Kavak Yetiştirme. ISSN: 1300-395X, 223 s, Özlem matbaası, İzmit.

Çanakçıŏlu H., Mol T. 1998. Orman Entomolojisi, Zararlı ve Yararlı Böcekler, ISBN: 975-404-487-2, İstanbul.

Güler N., Can P., Özay F., Ş., 1995/1. Cryptorhynchus lapathi L.'ye Karşı Mücadele, Kavak ve Hızlı Gelişen Tür orman Ağaçları Araştırma Enstitüsü Teknik Bülten No: 172, 25 s, İzmit.

Güler N., Can P. 1995/2. Kavak Fidanlıklarında Sciapteron tabaniformis Rott. Problemi, Kavak ve Hızlı Gelişen Tür orman
Ağaçları Araștırma Enstitüsü Teknik Bülten No: 173, 22 s, İzmit.

Kaplan M., Yücel A. 2014. Elazı ̆̆ İli Çilek Alanlarında Belirlenen Zararlı Böcek ve Akar Türleri, Meyvecilik Araştırma İstasyonu Müdürlüğü, 1(2), s, 7-14, Şanlıurfa.

Kaygın T.A. ve Yıldız Y., 2007. Bartın"da Söğüt ve Kavaklar için Tehdit Oluşturan Bir Tür: Crepidodera aurata (Marsh.) (Coleoptera, Chrysomelidae). Türkiye II. Bitki Koruma Kongresi 27-29 Ağustos 2007, Isparta.

Schimitschek., 1953. Türkiye Orman Böcekleri ve Muhiti (Çeviren Dr. Abdulgafur ACATAY) İstanbul Üniversitesi Yayınlar No: 556, Orman Fakültesi No: 24, 471 s, Hüsnütabiat matbaası, İstanbul.

Sekendiz O., A. 1974. Türkiye Hayvansal Kavak Zararlıları Üzerine Araştırmalar, Karadeniz Teknik Üniversitesi 62(3), 196 s, Çağlayan basımevi, İstanbul.

Selek F., Yaman M. ve Ünal S., 2014. Kavak Ağaçlandırma ve Fidanlıklarında Zarar Yapan Önemli Böcek Türleri. VIII. Milli Kavak Koordinatörlüğü Toplantısı 13-14 Kasım 2014, İzmit.

Şimşek Z., 1999. Şabanözü (Çankırı)'nde kavak alanlarında Söğüt koşnili (Chionaspis salicis (L.) ( Homoptera : Diaspididae )'nin yayılışı ve bulaşma oranları. Zonguldak Karaelmas Üniv. Bartın Orman Fak. Dergisi, Review of the Bartın Faculty of Forestry Zonguldak Karaelmas University, Cilt 1, Sayı: 2, 84-89.

Şimşek Z., 2002. Kenbağ Orman Fidanlığı (Çankırı)'nda bulunan Lepidoptera türlerinin tespiti üzerinde faunistik çalışmalar. II. Ulusal Karadeniz Ormancılık Kongresi Bildiriler Kitabı, Cilt II, 551-564.

Şimşek Z., 2005. Çankırı'da Kavak Fidanlıklarında Saydam Kanatlı Kavak Kelebeği [Paranthrene tabaniformis (Rott.) (Lepidoptera: Sesiidae)] ile Mücadele İmkânları Üzerinde 
Araştırmalar. Süleyman Demirel Üniversitesi Orman Fakültesi Dergisi 1: 84-103.

Tunçtaner K. 2008. Kavaklarda Genetik Islah ve Seleksiyon. ISSN: 1300-395X, 268 s, Özlem matbaas1, İzmit.

Url1,2014.http://www.agroatlas.ru/en/content/ pests/Melanogryllus_desertus/

Ünal, M. 1997. Kırıkkale Orthopter'lerinin

Fauna, Ekoloji ve Taksanomisi Üzerine Araştırmalar. Doktora tezi, Gazi Üniversitesi, Fen Bilimleri Enstitüsü, $51 \mathrm{~s}$, Ankara.

Ünal, M. 2006: Kırıkkale Orthopter'lerinin Fauna, Ekoloji ve Taksanomisi üzerine Araştırmalar, ISSN 1015-8243 Ankara.

Ünal S., Yaman, M., Ertürk, Ö., Selek, F., Karadeniz, M. 2014. Kastamonu ve Samsun Yöresinde Yaygın Kavak Zararlıları, VIII. Milli Kavak Koordinatörlüğü Toplantısı 13-14 Kasım 2014, İzmit.

Zeki, H., Toros, S., 1996. The effect of host on the adults of Chrysomela populi L. and Chrysomela tremulae F. (Col.:Chrysomelidae). Bitki Koruma Bülteni, 36: 25-38. 